\title{
Kajian Etnosains Madura dalam Proses Produksi Garam sebagai Media Pembelajaran IPA Terpadu
}

\author{
Wiwin Puspita Hadi ${ }^{1}$, Mochammad Ahied ${ }^{2}$ \\ Program Studi Pendidikan IPA Universitas Trunojoyo Madura \\ ${ }^{1}$ wiwin.puspitahadi@trunojoyo.ac.id
}

\begin{abstract}
ABSTRAK
Penelitian ini bertujuan untuk merekronstruksi pengetahuan asli masyarakat dalm proses produksi garam ke dalam pengetahuan ilmiah yang dijadikans sebagai media pembelajaran IPA Pengambilan data dilakukan di desa Padelegan dan desa Bunder Kecamatan Pademawu kabupaten Pamekasan.Metode penelitian yang dilakukan adalah kualitatif deskriptif dengan teknik pengambilan data melalui observasi, angket dan wawancara. Data yang diperoleh kemudian dianalisis, diverifikasi, dan direduksi kemudian dikontruski ke pengetahuan ilmiah dan diintepretasikan ke konsep sains yang ada di pembelajaran IPA. Hasil penelitian menunjukkan bahwa proses pembuatan garam yang dilakukan masyarakat dapat diinterpretasikan ke dalam pengetahuan sains dan diimplementasikan dalam pembelajaran IPA
\end{abstract}

Kata Kunci: etnosains, garam, pembelajaran IPA.

\begin{abstract}
This study was aimed to reconstruct science society into scientific knowledge in the production process of salt for learning material that was conducted salt farmers in Padelegan and Bunder Village, Pemekasan Regency, East Java Indonesia. The method of this study was qualitative descriptive with retrieval of data through direct observation, questionnaries, and interviews. The obtained data were analyze, veryfied, reduced and reconstruction into scientific knowledge and were interpreted. The focus of this study was tradition of salt process especially on knowledge of salt farmer about raw materials salt and crystalization of salt. The result showed that were five indigenous science from the salt production which could be recontructed into scientific knowledge.
\end{abstract}

Keywords: ethnoscience, salt, science learning. 


\section{PENDAHULUAN}

Pendidikan merupakan suatu
upaya untuk memberdayakan potensi manusia untuk mewariskan, mengembangkan dan membangun peradaban di masa yang akan datang. Salah satu upaya untuk membangun peradaban adalah dengan meningkatkan pemahaman terhadap lingkungan sekitar terutama yang berkaitan dengan budaya sebagai warisan dari generasi terdahulu. Budaya akan lebih dikenal apabila dimasukkan ke dalam kegiatan pembelajaran salah satunya adalah di bidang IPA. Nilainilai budaya yang merupakan kearifan lokal berbeda tergantung dari daerah masing-maisng terutama Indonesia yang terdiri dari berbagai suku, etnis, dan tradisi. Diharapkan dengan proses ini generasi muda akan semakin tinggi nilai nasionalisme dan bangga sebagai bangsa Indonesia

Pembelajaran ilmu sains yang memperhatikan kearifan budaya lokal sebagai jatidiri bangsa dan, karakter dan adat istiadat budaya lokal dinamakan pembelajaran berpendekatan etnosains Menurut Sudarmin (2015) pembelajaran berpendakat etnosain sangat penting karena Indonesia terdiri dari berbagai suku bangsa dan berbagai kebudayaan yang harus dilestarikan. Sudarmin\&Pujiastuti (2013) menyatakan bahwa pesan koservasi yang dicantumkan di papan pengumuman yang ada Taman Nasional Karimunjawa masih mempertahankan pengetahuan lokal, Sumarni (2016 menyatakan bahwa proses pembuatan gula kelapa dapat digunakan sebagai sumber belajar IPA dengan merekontruksi pengetahuan asli masyarakat ke pengetahuan ilmiah. Suastra (2010) menyebutkan bahwa guru-guru hampir $90 \%$ menyatakan berkeinginan untuk mengembangkan model pembelajaran sains berbasis budaya lokal namun ternyata hanya $20 \%$ yang memiliki kemampuan untuk melaksanakannya. Minimnya wawasan/pengetahuan guru untuk mencari contoh-contoh kejadian/peristiwa yang mengandung kearifan lokal yang ditunjukkan dengan rencana pelaksanaan pembelajaran yang disusun guru masih sedikit yang mengaitkan dengan budaya lokal. Oleh karena itu diharapkan dengan diintegrasikan nilai-nilai kearifan lokal dalam pembelajaran sains diharapkan pembelajaran sains menjadi lebih bermakna dan tidak hanya textbook oriented. Pengintegrasian diharapkan meningkatkan kepekaan siswa terhadap lingkungan sekitar. Di Madura sebagai salah satu suku di Indonesi juga kaya dengan khasanah budaya salah satunya adalah garam.

Pulau Madura identik dengan produksi garam dalam skala regional Jawa Timur maupun secara Nasional. Madura merupakan produsen garam terbesar se jawa timur dan nasional. Sehingga saat ini pun, Pulau Madura identik sebagai Pulau Garam. Garam merupakan komoditi yang penting karena banyak industri yang menggunakan garam sebagai bahan aditif, mulai industri makanan dan minuman hingga industri kimia klor dan alkali (CAP). Namun demikian sektor produksi garam secara nasional masih termarjinalkan karena daya saing SDM rendah, kapasitas produksi kecil dan dengan mutu garam yang tidak seragam. Sampai saat ini produksi garam dalam negeri hanya laku untuk garam konsumsi sedangkan garam 
industri semuanya masih impor dari negara lain. Iswahyudi dkk (2013) proses produksi garam rakyat melalui tahapan diantaranya penyediaan lahan (tambak), pengaliran air laut ke lahan, proses penguapan air laut, proses kristalisasi garam, pemisahan garam dari airnya sehingga diperoleh garam rakyat. Air sisa dari proses produksi garam rakyat berwarna kuning muda kemudian dibuang (tidak dimanfaatkan) disebut dengan air tua (bittern). Air tua (bittern) merupakan air limbah dari proses produksi garam rakyat. jumlahnya cukup besar sehingga diperlukan pengelolaan lebih lanjut.

Petani garam masih menggunakan cara tradisonal dalam kegiatan pengolahan garam. Pengetahuan yang mereka dapatkan berlangsung secara turun temurun berdasarkan kearifan lokal masyarakat Madura. Proses pembuatan garam yang sebenarnya tanpa mereka sadari bisa dikaji berkaitan dengan keilmuan yang disebut sebagai etnosains. Etnosains merupakan upaya untuk merekrostruksi pengetahuan asli masyarakat (indigeneous science) menjadi pengetahuan ilmiah (scientific kwowledge). Proses produksi garam harus dipelajari dari ilmu alam yang mendasari proses produksi yaitu kajian kimia dan fisika. Untuk itu harus ada kajian khusus yang bisa mendokumentasi dan mengidentifikasi kegiatankegiatan etnosains pada proses produksi garam sehingga diharapkan meningkatkan kemampuan petani garam. Selain itu hasil dari proses dokumentasi dan identifikasi terhadap kegiatan etnosains tersebut menjadi bisa menjadi sumber belajar kelPAan yang mengarah kepada perbaikan produksi garam dan kemandirian bangsa.

Tujuan dari penelitian ini untuk mengidentifikasi dan menjelaskan pengetahuan asli mayarakat dalam proses peroduksi garam yang masih dilakukan sampai sekarang meskipun sudah diikuti dengan kemajuan ilmu pengetahuan dan teknologi. Proses pembuaran garam diharapkan dapat menjadi sumbel belajar kontekstual bagi siswa. Selain itu diharapka bahwa memasukkan kearifan lokal ke dalam pembelajaran IPA dapat memacu siswa untuk berupaya menjadi penggerak dalam usaha meningkatkan

kesejahteraan

masyarakat sekitar.

\section{METODE PENELITIAN}

Penelitian ini dilakukan di desa Bunder dan desa Padelegan Kecamatan Pademawu Kabupaten Pamekasan. Lokasi ini dipilih karena merupakan sebagain besar wilayah merupakan lahan tambak garam. Metode penelitian yang digunakan adalah pendekatan kulitatif berbasis etnosain. Proses rekonstruksi difokuskan pada kegiatan yang dilakukan masyarakat pada pembuata garam di tambak garam untuk dikaitkan dengan sains. Pengambilan data meliputi data primer yang dikumpulkan melalui teknik observasi dan wawancara sedangkan data sekunder dengan studi literatur dan dokumen tentang proses pembuatan garam. Sumarni (2010) untuk memastikan tingkat kepercayaan terhadap data dilakukan dengan beberapa cara (1) mengadakan observasi secara intensif (2) triangulasi data dan metode; (3) menyiapkan referensi 
HASIL DAN PEMBAHASAN

Berdasarkan hasil observasi dan wawancara kepada petani garam diperoleh informasi bahwa proses produksi garam di tambak garam

dilakukan secara tradisional dan turun temurun dari nenek moyang.

Tabel 1. Hasil Rekontstruksi Pengetatuan Masyarakat menjadi Pengetahuan IImiah

\begin{tabular}{lll}
\hline No & Pertanyaan & $\begin{array}{c}\text { Sains } \\
\text { masyarakat }\end{array}$ \\
\hline 1 & $\begin{array}{l}\text { Tahukah yang } \\
\text { dimaksud } \\
\text { dengan } \\
\text { garam? }\end{array}$ & $\begin{array}{l}\text { Garam untuk } \\
\text { pelengkap } \\
\text { bumbu } \\
\text { masakan. } \\
\text { dengan bahasa } \\
\text { Madura "buje" }\end{array}$ \\
\hline 2 & Apakah bahan & Garam diperoleh \\
& baku garam? & dari air laut \\
& & \\
& & \\
& & \\
& & \\
& & \\
\hline 3 & Bagimana & \\
& pembuatan & Pembuatan \\
& garam? & garam dilakukan \\
& & dengan \\
& & menguapkan air \\
& & laut
\end{tabular}

\begin{tabular}{lll} 
& & \\
\hline 4 & Bagimana & Air laut \\
tahap yang & menguap dan \\
& terjadi pada & tinggal kristal \\
proses & garam \\
& terbentuknya & \\
kristal garam &
\end{tabular}

Garam merupakan kumpulan senyawa kimia yang bagian utamanya adalah natrium klorida $(\mathrm{NaCl})$ dengan zat-zat pengotor terdiri dari $\mathrm{CaSO}_{4}, \mathrm{MgSO}_{4}, \mathrm{MgCl}_{2}$

Konsep sains: unsur, senyawa, ikatan ionik

Garam dapat diperoleh dengan tiga cara yaitu penguapan air laut dengan sinar matahari, penambangan batuan garam (rock salt) dan dari air sumur garam. Cara yang banyak digunakan masyarakat adalah dengan penguapan air laut oleh sinar matahari

Konsep sains

Pemisahan campuran, perpindahan kalor Pembuatan garam dilakukan dengan beberapa kategori berdasarkan perbedaan kandungan $\mathrm{NaCl}$ nya yaitu penguapan dengan sinar matahari di ladang pembuatan garam dan kemudian terbentuk kristal dari senyawa $\mathrm{NaCl}$

Konsep sains

kristalisasi

Air laut yang berisi berbagai elemen dalam sistem periodik unsur.Air laut sebagai bahan utama pembuatan garam dialirkan ke petak-petak/kolam-kolam penguapan. Ketika air laut diuapkan maka berbagai jenis garam akan terbentuk. Air laut diuapkan sampai berkuran $60 \%$ dari volume awalnya. Setelah itu dialirkan ke kolam berikutnya sampai tahapan berikutnya terbentuk endapan $\mathrm{CaCO}_{3}$. Setelah $15 \%$ dari volume awal maka terbentuk endapan $\mathrm{CaSO}_{4}$. tahap selamjutmya adalah pengaturan pada konsentrasi air laut antara $25-29^{\circ} \mathrm{Be}$ dimana akan dieproleh kandungan $\mathrm{NaCl}$ maksimal.

Konsep sains:

Kelarutan dan Ksp 


\begin{tabular}{|c|c|c|c|}
\hline No & Pertanyaan & $\begin{array}{c}\text { Sains } \\
\text { masyarakat }\end{array}$ & Sains ilmiah \\
\hline 5 & $\begin{array}{l}\text { Mengapa } \\
\text { peminihan } \\
\text { dibuat sampai } \\
\text { empat tahap } \\
\text { dengan kadar } \\
\text { Be diantara } \\
25-29^{\circ} \mathrm{Be} ?\end{array}$ & $\begin{array}{l}\text { tidak tahu hanya } \\
\text { mengikuti } \\
\text { petunjuk dan } \\
\text { yang sudah } \\
\text { sering dilakukan }\end{array}$ & $\begin{array}{l}\text { Pada kristalisasi konsentrasi garam harus } \\
\text { antara } 25-29^{\circ} \mathrm{Be} \text { karena bila konsentrasi air } \\
\text { tua belum mencapai } 25^{\circ} \mathrm{Be} \text { maka } \mathrm{CaSO}_{4} \\
\text { yang akan banyak mengendap, sedangkan } \\
\text { jika lebih dari } 29^{\circ} \mathrm{Be} \text { maka garam-garam } \\
\text { mganesium yang akan mengendap yang } \\
\text { akan menimbulkan rasa pahit. } \\
\text { Konsep sains } \\
\text { sifat unsur dan senyawa }\end{array}$ \\
\hline 6 & $\begin{array}{l}\text { Bagaimana } \\
\text { mengetahui } \\
\text { kadar salinitas } \\
\text { di lahan } \\
\text { garam? }\end{array}$ & $\begin{array}{l}\text { dengan alat } \\
\text { yang dibeli di } \\
\text { toko dan tidak } \\
\text { tahu namanya }\end{array}$ & $\begin{array}{l}\text { Alat yang digunakan adalah Baumemeter } \\
\text { dalam skala Baume. Baumemeter adalah } \\
\text { alat yang digunakan untuk mengukur } \\
\text { kepadatan dari berbagfai cairan (mengukur } \\
\text { massa jenis dari suatu benda cair). Unit } \\
\text { skala Baumemeter dinotasikan dengan } \\
\text { derajat Baume }{ }^{\circ} \text { Be. Baume dari aquades } \\
\text { adalah } 0 \text {. Skala ini sering digunakan untuk } \\
\text { mengkur konsetrasi. } \\
\text { Konsep sains: } \\
\text { pengukuran konsentrasi }\end{array}$ \\
\hline 7 & $\begin{array}{l}\text { Mengapa } \\
\text { pada } \\
\text { peminihan ke } \\
4 \text { garam bisa } \\
\text { terjadi krital } \\
\text { garam? }\end{array}$ & $\begin{array}{l}\text { sudah dari } \\
\text { dahulu seperti } \\
\text { itu }\end{array}$ & $\begin{array}{l}\text { Proses pembentukan garam karena ada } \\
\text { kristalisasi. Kristalisasi adalah suatu } \\
\text { pembentukan partikel padatan di dalam } \\
\text { sebuah fasa homogen. Kristal garam } \\
\text { terbentuk dari larutan homogen air laut } \\
\text { dengan konsetrasi } 25-29^{\circ} \text { Be. Faktor yang } \\
\text { sangat berpengaruh pada ukuran kristal } \\
\text { adalah kecepatan nukleasi dan growth rate } \\
\text { yang dipengaruhi oleh supersaturasi. } \\
\text { Supersaturasi merupakan suatu kondisi } \\
\text { dimana konsentrasi padatan (solute) } \\
\text { dalam suatu larutan melebihi konsentrasi } \\
\text { jenuh larutan tersebut. Pembangkitan } \\
\text { supersaturasi salah satunya dilakukan } \\
\text { dengan penguapan solven melalui proses } \\
\text { evaporasi. Apabila pelarut pada suatu } \\
\text { larutan jenuh dikurangi maka konsentrasi } \\
\text { jenuh larutan tersebut akan turun sehingga } \\
\text { kondisi supersaturasi tercapai dan kristal } \\
\text { terbentuk. } \\
\text { Konsep sains: } \\
\text { larutan jenuh dan tak jenuh }\end{array}$ \\
\hline 8 & $\begin{array}{l}\text { Pada awal } \\
\text { kristal } \\
\text { beukuran kecil } \\
\text { makin lama } \\
\text { semakin besar } \\
\text { sehingga siap }\end{array}$ & $\begin{array}{l}\text { karena lama } \\
\text { direndam }\end{array}$ & $\begin{array}{l}\text { Kristal garam mengalami pertumbuhan. } \\
\text { Pertumbuhan kristal adalah bertambah } \\
\text { besarnya ukuran kristal. Kristal semakin } \\
\text { besar karena kristall tumbuh yang terjadi } \\
\text { dengan proses pembentukan kristal terdiri } \\
\text { dari dua tahap nukleasi primer dan } \\
\text { nukleasi sekunder. nukleasi primer atau }\end{array}$ \\
\hline
\end{tabular}




\begin{tabular}{|c|c|c|c|}
\hline No & Pertanyaan & $\begin{array}{c}\text { Sains } \\
\text { masyarakat }\end{array}$ & Sains ilmiah \\
\hline & $\begin{array}{l}\text { untuk } \\
\text { dipanen? }\end{array}$ & & $\begin{array}{l}\text { pembentukan inti yaitu tahap dimana } \\
\text { kristal-kristal mulai tumbuh namun belum } \\
\text { mengendap .semakin banyak inti yang } \\
\text { bergabung maka akan semakin cepat } \\
\text { pertumbuhan kristal tersebut. Tahap } \\
\text { selanjutnya adalah nukleasi sekunder } \\
\text { pada tahap ini pertumbuhan kristall } \\
\text { semakin cepat yang ditandai } \\
\text { menempelnya inti-inti menjadi kristal-kristal } \\
\text { padat. } \\
\text { Konsep sains: nukleasi dan pertumbuhan } \\
\text { kristal }\end{array}$ \\
\hline 9 & $\begin{array}{l}\text { Apa yang } \\
\text { anda ketahui } \\
\text { tentang } \\
\text { geosilator/geo } \\
\text { membran } \\
\text { pada } \\
\text { peminihan } \\
\text { tahap 4? }\end{array}$ & $\begin{array}{l}\text { pada tahap } \\
\text { pembentukan } \\
\text { kristal dilapisi } \\
\text { dengan alas }\end{array}$ & $\begin{array}{l}\text { merupakan teknologi baru yaitu } \\
\text { menggunakan terpal atau plastik HDPE } \\
\text { dengan ketebalan } 500 \text { mikron. } \\
\text { Konsep sains: } \\
\text { polimer }\end{array}$ \\
\hline 10 & $\begin{array}{l}\text { Mengapa } \\
\text { pada tahap } \\
\text { peminihan ke } \\
4 \text { perlu } \\
\text { dilakukan } \\
\text { pemadatan } \\
\text { tanah? }\end{array}$ & $\begin{array}{l}\text { Supaya air laut } \\
\text { tidak merembes } \\
\text { ke dalam tanah }\end{array}$ & $\begin{array}{l}\text { Porositas tanah mempengaruhi kecepatan } \\
\text { perembesan air lau ke dalam tanah, oleh } \\
\text { karean itu diperlukan pemadatan tanah. } \\
\text { Konsep sains } \\
\text { Struktur tanah }\end{array}$ \\
\hline
\end{tabular}

Dari tabel 1 dapat di dilihat bahwa proses pembuatan garam oleh petani garam dapat dikaitklan dengan kompetensi dasar di SMP berdasarkan kurikulum 2013 revisi antara lain adalah

Tabel 2. Hubungan Antara Proses Pembuatan Garam Dengan Kompetensi Dasar Di SMP

\begin{tabular}{|c|c|c|}
\hline No & Standar Kompetensi & $\begin{array}{c}\text { Konsep Sains dalam Proses Pembuatan } \\
\text { Garam }\end{array}$ \\
\hline 1 & $\begin{array}{l}\text { Menjelaskan konsep campuran } \\
\text { dan zat tunggal (unsur dan } \\
\text { senyawa), sifat fisika, dan kimia, } \\
\text { perubahan fisika dan kimia dalam }\end{array}$ & $\begin{array}{l}\text { Nama-nama senyawa yang terdapat dalam } \\
\text { air laut salah satunya garam dapur } \\
\text { Proses kristalisasi air laut menjadi garam }\end{array}$ \\
\hline 2 & $\begin{array}{l}\text { Menganalisis konsep suhu, } \\
\text { pemuaian, kalor, perpindahan } \\
\text { kalor dan penerapannya dalam } \\
\text { kehidupan sehari-hari termasuk } \\
\text { mekanisme menjaga kestabilan } \\
\text { suhu tubuh pada manusia dan } \\
\text { hewan }\end{array}$ & $\begin{array}{l}\text { Proses penguapan karena adanya sinar } \\
\text { matahari yang merupakan perpindahan } \\
\text { kalor secara radiasi } \\
\text { Tiap kolam peminihan mempunyai rentang } \\
\text { waktu dalam proses penguapannya } \\
\text { tergantung dari kapasitas panas sinar } \\
\text { matahari dan angin. }\end{array}$ \\
\hline
\end{tabular}




\section{SIMPULAN}

Berdasarkan hasil penelitian diperoleh bahwa proses produksi garam yang merupakan pengetahuan yang diperoleh secara turum temurun dapat dianalisis dari konsep-konsep ilmiah sehingga dapat menjadi sumber belajar bagi siswa. Guru diharapkan mampu mengkorelasikan antara

\section{DAFTAR PUSTAKA}

Cakraborty, D.\&Patey, G.N. 2013. How Crystal Nucleate and grow in Aqueous $\mathrm{NaCl}$ Solution. The Journal. of Physics Chem Letters. 4, 573-578

Fachry, AR., Tumanggor, J., \& Yuni

L. 2008. Pengaruh Waktu

Kristalisasi Dengan Proses

Pendinginan Terhadap

Pertumbuhan Kristal

Amonium Sulfat Dari Larutannya. Jurnal Teknik Kimia, Vol 15 No 2, 9-16

Geertman, R.M. 2000. Sodium Chloride: Cristallization. Netherlands: Academic Press p. 4127

Herman \& Joetra W. 2015. Pengaruh Garam Dapur (NaCl) Terhadap Kembang Susut Tanah Lempung. Jurnal Momentum, Vol 17 No 1.13-20

Iswahyudi, Muharrami, Supriyanto. 2013. Pengolahan limbah gram (bittern) menjadi struvite degan [engontrolan $\mathrm{pH}$ Prosiding Disajikan Dalam Seminar Nasional; Trunojoyo Madura University

Mustofa\&Turjoyo, E. 2015. Analsis Optimalisasi Terhadap Aktivitas Petani Garam Hilir di Penambangan Probolinggo. J. WIGA, Vol 5 No 1, 46-57 pengetahuan masyarakat dengan konsep-konsep sains yang ada disekolah sehingga diharapakan pembelajaran menjadi lebih bermakna. Saran untuk penelitian selanjutnya adalah menggali lagi tradisi dan budaya yang ada di madura untuk dapat dikonstruksi menjadi pengetahuan ilmiah untuk menjadi sumber belajar bagi siswa.

Rawajfeh, K., Al Hunaidi, T., Saidan, M., \& Al Hamamre, Z. 2014. Upgrading of Commercial Potassium Chloride by Crystallization : Study of Parameters Aggecting yhe Process. Life Science Journal. Vol 11.6

Rositawati A.G., Taslim, C.M., \& Soetrisnanto, D.2013. Reskristalisasi Garam Rakyat Dari Daerah Demak Untuk Mencapai SNI Garam

Sumarni, W., Sudarmin., Wiyanti\& Supartono. 2016. The Recontruction of Society Indigenous Science into Scientific Knowledge in the Production Process of Palm Sugar Journal of Turkish Science Education: Vol 13 No. 4.281

Suastra, I. 2010. Model Pembelajaran Sains Berbasis Budaya Lokal Untuk Mengembangkan Kompetensi Dasar Sains Dan Nilai Kearifan Lokal di SMP. J. Pendidikan dan Pengajaran. 43 No 2. 8-16

Sudarmin \& Pujiastuti, E. 2015.Scientific Knowledge Based Culture and Local Wisdom in Karimunjawa for Growing Soft Skills Conservation International Journal of Science and Research, 4, 598-604 
86 Jurnal Rekayasa Vol 10 No 2, Oktober 2017, hlm. 79-86

Widayat. 2009. Production of

Concentration by using Industry Salt With

Sedimentation-Microfiltration

Surface response

methodology. Teknik Vol 30

Process: Optimazation of

No $1,11-1$

Temperature and 